\title{
O problema da transmissão textual entre os dois Fulgêncios
}

\author{
The problem of textual \\ transmission between the two \\ Fulgentius
}

\author{
Cristóvão José dos Santos Júnior ${ }^{1}$ \\ http://orcid.org/0000-0002-5797-7192
}

Resumo: Este trabalho busca evidenciar o problema de transmissão dos escritos fulgencianos, imprescindível para a compreensão da autoria. Nesse sentido, ressalta-se a confusão realizada no processo de atribuição de alguns títulos, atualmente creditados a Fábio Plancíades Fulgêncio (Mitógrafo), a seu homônimo Fábio Cláudio Gordiano Fulgêncio (Ruspense), na medida em que a biografia daquele não apresenta vasta documentação comprobatória supérstite, tendo sido nutridas inúmeras discussões a seu respeito. Para seu conhecimento, muitos investigadores usam fontes indiretas, que englobam citações feitas por outros escritores e referências intratextuais, havendo especial destaque para o prólogo do livro I das Mythologiae. Dessa forma, resta evidenciado que o entendimento da autoria fulgenciana não é tarefa de ordem meramente descritiva, requerendo um olhar filológico atento.

Palavras-chave: Transmissão textual; Autoria; Latim africano; Antiguidade tardia; Literatura marginalizada.

Abstract: This work seeks to highlight the problem of transmission of fulgencian writings, essential for the understanding of authorship. In this sense, the confusion in the attribution process of some titles, currently credited to Fabius Planciades Fulgentius (Mythographer), to his namesake Fabius Claudius Gordianus Fulgentius (of Ruspe) is highlighted, since the biography of the latter does not present extensive supporting documentation and numerous discussions have been held about it. To his knowledge, many researchers use indirect sources, which include quotations made by other writers and intratextual references, with special emphasis on the prologue to the

\footnotetext{
${ }^{1}$ Doutorando do Programa de Pós-graduação em Literatura e Cultura do Instituto de Letras da Universidade Federal da Bahia. E-mail: cristovao_jsjb@hotmail.com
} 
book I of Mythologiae. In this way, it remains evident that the understanding of the Fulgencian authorship is not a merely descriptive task, requiring an attentive philological view.

Keywords: Textual transmission; Authorship; African Latin; Late antiquity; Marginalized literature.

\section{Situando o problema}

A biografia de Fábio Plancíades Fulgêncio ainda representa um enigma histórico, tendo em vista a escassez de dados para seu conhecimento. Do pouco que se sabe sobre sua vida, parte considerável está adstrita ao prólogo do Livro I de suas Mythologiae, tendo sido alimentadas, ao longo do tempo, inúmeras dúvidas e debates sobre sua existência.

Acrescente-se a isso uma confusão realizada por estudiosos quanto à imputação da autoria de alguns livros, na medida em que determinados títulos foram, por vezes, creditados a um homônimo, habitante da cidade de Ruspe, em decorrência de um peculiar processo de transmissão dos escritos. Assim, atentando para o fato de que o entendimento dessa paternidade artística está intimamente relacionado ao processo de transmissão textual, buscou-se, estrategicamente, discutir a autoria fulgenciana a partir do tensionamento dessa problemática.

Dessa forma, apresentam-se, inicialmente, alguns elementos ligados à fortuna dos dois Fulgêncios. Posteriormente, são oferecidas determinadas informações sobre o Bispo de Ruspe, a exemplo de dados biográficos e relativos à temática de sua escrita. Por fim, expõem-se os textos que integram o cabedal fulgenciano, realizando-se um exame sintético de referências intratextuais consideradas úteis ao conhecimento de sua biografia e presentes em suas obras (Mythologiae, Sermonum, Virgilianae e De aetatibus).

\section{Alguns elementos da fortuna fulgenciana}

A fortuna fulgenciana foi marcada pela atribuição de alguns títulos a seu homônimo Ruspense, de tal maneira que é imprescindível discutir quais seriam os elementos adotados no processo de diferenciação. Ressalte-se, portanto, que a biografia do autor Fulgêncio está diretamente atravessada pelo problema da transmissão de seu acervo, que foi objeto de diferentes considerações, tanto em sua tradição manuscrita, como na impressa.

Fruto das inúmeras divergências teóricas articuladas ao redor da incógnita existencial de nosso autor, seus comentadores, gradualmente, sedimentaram duas perspectivas distintas. A 
primeira seria uma hipótese monística, singularista ou unitária, enquanto a segunda já se refere a uma hipótese dualista, separatista, dicotômica, bipartida ou pluralista.

Conforme a visão monista, sempre houve apenas um Fulgêncio, de modo que os aparentes equívocos, quanto ao manifesto antagonismo na imputação de suas obras, seriam apenas um caso de existência de denominações distintas para o mesmo sujeito. Atualmente, todavia, predomina a concepção dicotômica, na medida em que muitos estudiosos consideram a ocorrência de marcas estilísticas profundamente diversas entre as obras, de tal sorte que seria improvável que apenas um único indivíduo tivesse escrito de forma tão variada.

Os defensores do singularismo, contudo, advertem para a possível configuração de anacronismos, de modo que não se deve negligenciar a chance de a escrita fulgenciana se revestir, de fato, de uma potente versatilidade. Assim, conforme os unitaristas, Fulgêncio apresentaria uma obra dividida em fases. Dessa maneira, haveria, de um lado, uma produção de feição mais pagã, fruto dos esforços empreendidos em sua juventude, enquanto, de outro, existiria um legado de cunho teológico-cristão, correspondendo a um período de maior maturidade.

De qualquer maneira, ainda que, hodiernamente, o prisma monista seja menos aceito, deve-se atentar para o fato de serem inegáveis os pontos de conectividade entre os dois Fulgêncios, mesmo que tomados separadamente. Ambos seriam, até para os causídicos da dicotomia, aristocratas, africanos, cristãos e estudiosos de grego e de latim.

Além disso, deve-se também atentar para certo comodismo da perspectiva unitária, já que a vida do Fulgêncio Ruspense está fartamente documentada, resolvendo-se, de pronto, toda uma querela envolvendo a necessidade de grandes indagações quanto à existência do Mitógrafo. Assim, para os que defendem que há apenas um autor, não é preciso se debruçar em maiores perquirições, já que os elementos biográficos do Bispo de Ruspe estão mais largamente disponíveis.

Os que advogam pelo pluralismo, contudo, esbarram em uma enorme dificuldade para o exame de sua história. Nessa árdua empreitada, tais pesquisadores levam em consideração referências intratextuais presentes em sua produção, com especial enfoque para o prólogo do Livro I das Mythologiae, citações de outros autores, estudos relativos à estilística e dados histórico-filológicos.

Em seu minucioso estudo a respeito do prefácio das Mitologias, Venuti (2009) aponta a realização de um stemma codicum por Jungmann em 1871. Esse contributo científico foi, de fato, paradigmático para os estudos fulgencianos, tendo em vista que serviu de parâmetro para a fixação das obras, analisando-se, criticamente, um conjunto de códices, relativo à sua tradição 
manuscrita2.

A tradição impressa, por sua vez, também juntou obras dos dois Fulgêncios num único volume como se apenas um fosse, seguindo a tradição manuscrita. A editio princeps, intitulada Enarrationes allegoricae fabularum Fulgentii Planciadis, foi publicada em 1498 sob responsabilidade de Giovanni Battista Pio. Essa edição inclui as Mythologiae e a Sermonum, tendo sido reimpressa em 1521 por Jacob Locher (VENUTI, 2018).

Em 1535, Jacob Moltzer publicou uma nova edição na Basileia, indicando que a autoria das Mythologiae e da Sermonum seriam do Bispo. No ano seguinte, Henricus Petrus realizou nova edição, em que o autor das Mythologiae também seria o Ruspense. Em 1556, Petrus acrescentou outras obras, de natureza teológica e doutrinal. Em 1599, Hieronymus Commelinus publicou uma nova versão em Heidelberg, englobando as Mythologiae e a Virgilianae. Nos séculos XVII e XVIII, houve novas edições, como a de Muncker (1681) e a de Augustinus van Staveren (1742), com as Mythologiae, a Sermonum e a Virgilianae, as três obras fulgencianas até então mais difundidas (VENUTI, 2018).

Apenas no final do século XIX, houve a inclusão da De aetatibus, através da primeira edição crítica do legado fulgenciano, que foi fixada por Helm em 1898 e reimpressa em 1970, acrescida de um adendo bibliográfico de autoria de Jean Préaux. Dentre as produções elencadas em sua edição, encontra-se, além das quatro obras atualmente atribuídas ao Mitógrafo, o opúsculo intitulado Super Thebaiden, creditado ao Ruspense. Nessa edição, desperta curiosidade o fato de aparecerem três nomes diversos para Fulgêncio: Sanctus Fulgentius Episcopus, Fabius Planciades Fulgentius e Fabius Claudius Gordianus Fulgentius.

Embora Helm tenha, realmente, apresentado uma tríade fulgenciana, não era ele partidário de uma perspectiva separatista ternária. Ocorre que, conquanto considerasse apenas a existência de um Fulgêncio, acolhendo a perspectiva singularista, ele empregou um critério conservador para a atribuição das obras, ressaltando as denominações existentes nos códices.

Segundo Manca (2003), o posicionamento de Jungmann foi divisor de águas para o processo de atribuição da De aetatibus a Fábio Plancíades Fulgêncio. Para tal pesquisador, a mixórdia antonomástica deriva da intervenção errônea de algum escriba douto, que, por via de sua autoridade, possibilitou o perpetuamento da incorreta atribuição ao Ruspense.

\footnotetext{
${ }^{2}$ Para um estudo em língua portuguesa da tradição impressa do acervo ligado à problemática dos dois Fulgêncios (Ruspense e Mitógrafo), indica-se o trabalho realizado por Raul Oliveira Moreira em sua Dissertação de Mestrado, intitulada A "Exposição dos conteúdos de Virgílio", de Fulgêncio: estudo introdutório e tradução anotada, que foi objeto de defesa em 2018, encontrando-se disponível no sítio eletrônico seguinte: https://repositorio.ufba.br/ri/handle/ri/26692.
} 
De modo a exemplificar a resistência temporal desse equívoco, que se arrastou por séculos, é oportuno recordar os seguintes dizeres de Sigisberto de Gembloux, um crítico do século XI:

\begin{abstract}
Fulgentius Ruspensis episcopus [...] scripsit libros, quos pretitulavit, 'sine litteris': librum scilicet de Adam sine A; de Abel sine B; de Cain sine C; et ceteros libros secundum consequentiam litterarum. O bispo Fulgêncio Ruspense [...] escreveu livros, os quais denominou 'sem as letras': ou seja, o livro de Adão sem a, de Abel sem b, de Caim sem c, e os livros remanescentes conforme as letras seguintes.
\end{abstract}

Extraído de sua obra De scriptoribus ecclesiasticis (1974), o retrocitado fragmento indica não apenas a duradoura vivacidade da atribuição do lipograma ao Ruspense, como inclusive a falta de confiabilidade dessa imputação, tendo em vista que sugere o desconhecimento do escrito em relevo. Sigisberto fala sobre uma produção que provavelmente ignora, na medida em que atribui a Abel o livro Ausente $B$ e a Caim o Ausente $C$, personagens integrantes, em realidade, da primeira narrativa, marcada pela restrição em 'a'. É possível, contudo, que ele só estivesse buscando demonstrar a natureza lipogramática da obra de modo que fosse compreendido de forma mais imediata por seu leitor.

Esse dado é muito relevante para o entendimento da confusão realizada, pois sugere o mecanismo de difusão de informações falsas tomadas a partir de fontes indiretas. Durante a Idade Média, a aquisição de livros era extremamente difícil, como também o era o acesso aos manuscritos de referência, de tal sorte que não é custoso concordar com Jungmann, quando alega descuido dos copistas, tendo em vista as notórias limitações que acometiam a empreitada filológica no Medievo.

Ademais, a hipótese jungmanniana ganhou força a partir dos subsídios hermenêuticos fornecidos por Jacob Hommey (1696), que considerou o estilo plasmado no lipograma deveras distanciado daquele do Bispo. Também analisando elementos estilísticos e o próprio conteúdo da obra, Fabio Rosa (1997) o aproximou daquele da Virgilianae, asseverando que em ambos estaria presente a temática das Idades.

No lipograma, essa questão já se explicita, até mesmo, em seu título. Ali, narra-se o itinerário humano desde o pecado original em que se aterrou o ócio paradisíaco fornecido pelo jardim do Éden, até o período dos imperadores cristãos, passando por figuras como Noé, Abraão, Moisés, Saul e Cristo. Na Virgilianae, por sua vez, os erros de Eneias impulsionam seu amadurecimento, de modo que suas ações poderiam ser enquadradas em diferentes etapas da vida humana.

A análise estilística do conjunto de toda a obra creditada a Fulgêncio inspirou um vasto 
campo de indagações. Se, por um lado, há autores que, como Rosa, evidenciam pontos de aproximação entre o lipograma e os demais escritos, por outro, existem estudiosos que também ressaltam aspectos distanciadores.

Nesses termos, Reifferscheid (1883), embora concluindo pelo pertencimento da De aetatibus ao Mitógrafo, alerta para o emprego de um latim menos adequado à tradição normativa, rico, até mesmo, em simplificações gráficas, a exemplo da visualizada com os ditongos. Manca (2003), noutra linha de intelecção, justifica tal uso por força do apelo oral consubstanciado no lipograma, advertindo para as possíveis variações linguísticas, em estado de concorrência, que teriam permeado o latim tardio. Além disso, este último pesquisador, partindo de contributos de Jungmann (1877) e Pennisi (1963), enfatiza a existência de uma série de semelhanças morfossintáticas entre passagens do lipograma e determinados excertos das três outras obras do Mitógrafo.

Tais discussões se demonstram tão frutíferas justamente por decorrerem da instabilidade do texto fonte, vinculada a uma tradição manuscrita complexa e marcada pela atividade de escribas com perfis diversos. Nesse sentido, existem aqueles que atuavam com um maior grau de intervenção, corrigindo mais detidamente o texto, e os que transparecem não ter interferido tanto assim. Além disso, deve-se notar que são poucos os códices supérstites, sendo que, dentre estes, a maioria apresenta consideráveis mutilações, denunciando-se o extravio de várias passagens.

Observados tais elementos ligados à fortuna fulgenciana, cabe agora conhecer um pouco a respeito do Bispo de Ruspe, para, em seguida, confrontá-lo com o Mitógrafo, facilitando-se ainda mais o entendimento do procedimento de atribuição de seu legado.

\section{Fulgêncio Ruspense}

Visto que a hipótese dualista atualmente prevalece, faz-se necessária a utilização de epítetos como forma de diferenciar os homônimos. Assim, o autor de nosso lipograma é conhecido como Fulgêncio Mitógrafo, enquanto o Bispo é denominado por Fulgêncio Ruspense. A alcunha de Mitógrafo decorre da grande disseminação de suas Mythologiae, obra mais difundida de seu legado. O prosônimo Ruspense, por sua vez, concerne ao fato de que o clérigo era habitante da cidade de Ruspe, situada no norte do continente africano e, à época, dominada 
pelos bárbaros ${ }^{3}$ germânicos conhecidos por vândalos.

Muitos dados relativos à biografia de Fábio Cláudio Gordiano Fulgêncio, o Bispo, são extraídos da obra Vita Fulgentii, creditada ao estudioso Ferrandus. Além de padecer de uma atribuição controversa, tal escrito carece de datações explícitas, razão pela qual os historiadores buscam uma reconstituição parcial da vida do Ruspense também a partir de referências indiretas (MODÉRAN, 1993).

Nesse sentido, há muitas considerações, até mesmo específicas, tomadas como seguras para o conhecimento do Epíscopo, mas que ainda tropeçam em uma dificuldade de fixação cronológica. Assim, a título de exemplo, sabe-se que ele foi bispo por vinte e cinco anos e que estava em seu sexagésimo quinto ano quando, em primeiro de janeiro, faleceu, tendo sido sepultado no dia seguinte e sucedido no episcopado um ano após, pelo teólogo Felicianus. Não se encontram, todavia, datas que evidenciem os anos em que esses fatos ocorreram, exigindose um esforço dos investigadores para estabelecer aproximações temporais em face dos dados referenciados (ENO, 1996).

Esse membro da Igreja Católica provavelmente viveu entre os anos 467 e 532 d.C., tendo nascido em Telepte, situada na província de Bizacena, ao sul de Cartago, e morrido em Ruspe, localizada na atual Tunísia. Além disso, considerando seu falecimento em 532 d.C., é oportuno notar que o bispo de Ruspe não presenciou por pouco a retomada do norte africano pelos romanos, empreendida pelo imperador oriental Justiniano em 533 d.C. Ante isso, deve-se recordar que, em 476 d.C., conformou-se apenas a queda do Império Romano Ocidental, preservando-se a organização política situada à leste.

Tal epíscopo foi considerado o maior teólogo de seu tempo, notabilizando-se pela propagação da doutrina agostiniana e pelo contundente combate ao pelagianismo e ao arianismo. Desse modo, é válido lembrar que Santo Agostinho, maior influência do Fulgêncio Ruspense, foi o grande expoente da Patrística, que diz respeito à primeira fase da filosofia medieval, em que se buscava a racionalização, em um viés maniqueísta e neoplatônico, da fé cristã, estruturando dogmas capazes de fomentar a difusão do catolicismo, a exemplo da doutrina do pecado original, que dispõe a graça de Cristo ser fundamental para a redenção humana.

${ }^{3} \mathrm{O}$ termo bárbaro aqui empregado não deve ser compreendido em um viés pejorativo ou etnocêntrico, referindo-se tão somente a povos que, em princípio, estavam mais alheios à cultura e à língua dos antigos romanos. Note-se, ademais, que muitas dessas sociedades assimilaram, gradualmente, elementos ligados à pretérita civilização do Lácio, a qual, inclusive, exerceu, com o latim, influências de substrato linguístico. 
Assim, opunha-se ao pelagianismo, que, recusando a ideia do pecado original, defendia ser o homem absolutamente responsável pela sua salvação, instante em que seria desnecessária a graça divina, e ao arianismo, que negava a Santíssima Trindade e o caráter divino de Jesus Cristo.

Como resultado desse embate ideológico-doutrinário, o Bispo conquistou a inimizade do rei ariano Trasamundo, que o exilou na Sardenha. Quando este líder vândalo morreu, foi sucedido por Hilderico que era neto do imperador romano Valentiniano III e, articulando um projeto de romanização, favoreceu os católicos, permitindo o retorno de Fulgêncio.

A obra do Ruspense demonstra reflexos de sua vida religiosa combativa. Nela, o clérigo defende fervorosamente o dogma da Santíssima Trindade e a ideia de predestinação. Ressaltese, por fim, que, dentre os escritos que lhe são atribuídos, destacam-se os seguintes: Contra Arianos, Contra Fabianum, De Trinitate, Ad Trasimundum regem, Ad Donatum liber de fide orthodoxa ed diversis erroribus haereticoru, Ad Petrum diaconum de fide, De veritate praedestinationis et gratiae Die, De remissione peccatorum e De Incarnatione filii Dei.

\section{Fulgêncio Mitógrafo}

Se, por um lado, a biografia de Fábio Cláudio Gordiano Fulgêncio se revela conhecida, por outro, a vida de Fábio Plancíades Fulgêncio ainda se reveste de um caráter enigmático. A diferença do evidenciado com o Bispo, nenhum biógrafo medieval parece ter se dedicado ao amplo registro da história do Mitógrafo. Assim, ponderando a existência de inúmeras lacunas e a escassez de dados oficiais para seu conhecimento, a crítica costuma considerar uma série de elementos estilísticos e referências intratextuais, com ênfase para o prefácio do Livro I das Mythologiae, além de citações realizadas por outros autores. Dessa forma, a trajetória existencial de Fulgêncio passa a ser concebida, sobretudo, a partir de informações fornecidas pelo próprio em uma obra artística, o que deve ser objeto de algumas ressalvas.

Assume-se, aqui, uma postura incisivamente cética quanto à confiabilidade do teor informativo dos textos literários, razão pela qual se mantém um tom cauteloso acerca da realização de afirmações referentes à biografia de Fulgêncio. Impende destacar, entretanto, que este pesquisador não despreza as pesquisas e conjecturas até então formuladas a respeito da vida de Fulgêncio, considerando, principalmente, a peculiaridade de sua circunstância. Ainda que tensionando essas informações em estado de alerta, importa avaliar tais discussões como úteis para a compreensão de seu acervo, na medida em que esmiúçam e desnudam inúmeros 
elementos encontrados nas obras.

Desse modo, o perigo não está propriamente nas lucubrações hermenêuticas, mas sim em como elas são apresentadas pelo pesquisador e recepcionadas pelo público leitor. Nesse sentido, advertem, inclusive, Hays4 (1996) e Venuti (2009) que muitas informações contidas na produção fulgenciana, a exemplo das circunstâncias sociais calamitosas descritas nos prólogos, como guerras e invasões, podem se tratar de mero tópos literário. De qualquer modo, na pior das hipóteses, essas considerações são, pelo menos, proveitosas para o conhecimento da própria obra.

Além disso, esse modus operandi também fornece informações objetivas, não se pautando simplesmente em divagações de cunho estilístico, outra razão para o leitor não desprezar as páginas que se seguem. De modo ilustrativo, as referências feitas por Fulgêncio servem à datação de sua obra, visto que quando o Mitógrafo faz alusão a autores ou a fatos históricos, por decorrência lógica, já se sabe que ele teve que ser, no mínimo, contemporâneo, desses acontecimentos e escritores.

Assim, analisando um conjunto de dados, quanto ao eixo espaço-temporal, a crítica considera que suas obras foram elaboradas durante a Antiguidade Tardia no norte do continente africano entre o final do século $\mathrm{V}$ e início do século $\mathrm{VI}$, em um contexto assinalado por uma veemente propagação da fé católica. A obra fulgenciana pertence, portanto, ao momento em que o Império Romano do Ocidente já havia sucumbido às invasões germânicas, e o cristianismo ocupava um lugar de centralidade, em substituição às crenças politeístas, que inspiraram os mitos clássicos.

Desse modo, Fulgêncio assumiu um importante papel de conservação da cultura greco-romana no Medievo, efetuando releituras cristãs de temáticas antigas, a exemplo da mitológica. Seus escritos se apoiam, portanto, em uma tradição pagã, remodelada por novos costumes, no que se explicita tanto o elevado acervo cultural do autor quanto sua inventividade.

Tal escritor deixou uma herança considerável, senão pela extensão, ao menos pela difusão e por retomadas posteriores. Seus comentadores the atribuem as publicações das Mythologiae, Expositio sermonum antiquorum, Expositio Virgilianae Continentiae e do lipograma De aetatibus mundi et hominis. Essa produção está praticamente meio milênio afastada do período considerado clássico e já situada na conjuntura pré-carolíngia ou merovíngia de formação dos romances, no que se deve enfatizar que o referido autor provavelmente estudou

\footnotetext{
${ }^{4}$ Hays elaborou uma tese rica em detalhes sobre a vida do Mitógrafo e disponibilizou, em sítio eletrônico, sua bibliografia completa, com última atualização em 2013.
} 
latim como uma língua estrangeira de cultura, não a tendo por língua nativa. Some-se a isso o cenário sócio-histórico de dominação vandálica, marcado por fortes conturbações políticas, do que muitas vezes decorria a intensa restrição de acesso a livros e a necessidade de realização de citações e referências literárias por memória.

Fulgêncio foi um dos mitógrafos mais lidos da Idade Média, influenciando autores como Dante, Petrarca, Boccaccio e os mitógrafos do Vaticano, de modo a integrar uma tradição literária notável. Dentre os fatores que contribuíram para seu apagamento, podem-se destacar sua origem africana, que possibilitou um afastamento do eixo de sedimentação canônica, seu estilo rebuscado e, por vezes, truncado, bem como sua escrita lipogramática, considerada por muitos como mero jogo linguístico.

Deve-se evidenciar, todavia, que ele não foi poupado de críticas, as quais alcançam, em dados instantes, o degrau acérrimo das condenações ideológicas. De modo ilustrativo, podem ser mencionadas as apreciações de Comparetti (1943), o qual acusou Fulgêncio de deficiência cognitiva, bem como as considerações de Strzelecki (1952), que chegou a definir a obra do aludido autor como "esterco literário".

Outrossim, seu lipograma foi por muitos julgado como resultado de mero experimentalismo linguístico, sendo supostamente desprovido de grande valor literário, na medida em que a escrita com omissão de letras do alfabeto implicaria uma restrição que não seria recompensada com um efeito estético, passando muitas vezes despercebida, diferentemente do observável no uso de outros modelos restritivos, reputados apreciáveis, a exemplo do emprego de métrica e de cadência poética.

A importância de Fulgêncio se impunha, de fato, pela própria difusão de seus escritos, já que foi um dos mitógrafos mais lidos no Medievo, mas também por fornecer uma visão do homem medieval sobre a Antiguidade, de modo que sua obra também apresenta significativo valor histórico. Dessa forma, este estudo é também relevante para que se elucidem melhor os desdobramentos da tradição cultural clássica.

Visto que a compreensão da vida de Fulgêncio se confunde com o estudo de sua obra, impõe-se a suscinta observância de sua herança literária. Assim, no que tange às Mythologiae, será recuperado o trabalho de José Amarante (2019). Quanto à Expositio Sermonum Antiquorum, resgatar-se-á o estudo efetuado por Shirlei Almeida (2018). No que diz respeito à apreciação da Expositio Virgilianae Continentiae, serão evidenciadas as contribuições de Raul Moreira (2018). Por fim, no que concerne à De aetatibus, serão utilizadas traduções aqui propostas. 


\section{Mythologiae}

Como já dito, as Mythologiae correspondem ao texto mais conhecido de Fábio Plancíades Fulgêncio, sendo responsáveis, inclusive, por sua alcunha de Mitógrafo. Tal escrito contrasta com a De aetatibus, visto que se refere a uma obra de feição mais pagã, marcada por narrativas envolvendo personagens da Mitologia greco-romana, enquanto esta já concerne a uma produção nitidamente cristã, caracterizada por descrições literárias de acontecimentos bíblicos.

Impende frisar, entretanto, que esse aparente distanciamento temático-ideológico deve ser mitigado pela perspectiva articulada nas descrições mitológicas. Na prática, o autor remodela a cultura antiga ao tempero de sua época, tensionando o acervo que lhe fora pretérito sob uma ótica moral cristã.

Esse elemento religioso foi motivo de grande valorização de seu legado na conjuntura medieval. Possibilitou-se, assim, tanto uma significativa difusão de seus títulos como de um conteúdo poético que já se encontrava em vias de restrição, por causa da dificuldade em se produzir livros e pela busca por apagamento de elementos que contradissessem a dogmática católica.

Afinal, como seria possível explicar para a cristandade medieval mitos que envolviam relações homoafetivas, a exemplo da estabelecida entre Zeus e Ganimedes, ou os associados à transgeneridade, como o relativo à mudança de sexo de Tirésias, encarados com significativa naturalidade pelos romanos do período clássico? É justamente nesse cenário que se insere a escrita fulgenciana, buscando recompor e justificar determinados elementos míticos.

O pesquisador Amarante (2018) evidencia muito bem esse aspecto, ressaltando a existência de um amálgama pagão-cristão nas Mythologiae, partindo de uma análise minuciosa da fábula inicial Vnde Idolum (Sobre a origem dos ídolos), considerada texto programático estabelecedor de diretrizes hermenêuticas para a compreensão dos demais mitos. Tal estudioso defende que essa obra fulgenciana está estruturada em uma costura horizontal, apresentando, até mesmo, uma feição didática, que se vincula à busca por uma certa justificação de cunho interpretativo, a qual está diretamente associada ao emprego de explicações de cunho moral e 
algumas, até mesmo, evemeristas de viés lactanciano ${ }^{5}$.

Quanto às referências intratextuais consideradas no método de conhecimento do autor, há três passagens do prefácio que merecem destaque:

Sed quia numquam est malum inmortale mortalibus, tandem domini regis felicitas adventantis uelut solis crepusculum mundo tenebris dehiscentibus pauores abstersit ${ }^{6}$. [...] quibus adhuc inpressae bellantium plantae mauricatos quod aiunt sigillauerunt gressus et formidine menti nondum extersa hostes in uestigiis pauebamus ${ }^{7}[. .$.$] Galeni curia exclusisset, quae$ pene cunctis Alexandriae ita est inserta angiportis, quo cirurgicae carnificinae laniola pluriora habitaculis numerentur ${ }^{8}$.

Mas porque jamais o mal é imortal aos mortais, enfim a boa sorte de um rei soberano que está chegando fez desaparecer os medos, como o crepúsculo do sol, com as sombras se abrindo ao mundo. [...] sobre as quais, ainda afundadas, as pisadas dos combatentes - como se costuma dizer muricatos - marcaram os seus passos e, com o temor ainda não limpo da mente, temíamos os inimigos por meio das suas pegadas [...] a cúria de Galeno, mais cruel do que as guerras, ela que está disseminada assim em quase todos os becos de Alexandria, de forma que podem ser contados mais pequenos açougues de carnificina cirúrgica que habitações.

Note-se que os três fragmentos fazem alusão à uma conjuntura social conturbada, de tal sorte que o autor, vitimado por uma circunstância belicosa, almejaria a chegada de um novo soberano. Assim, há quem entenda que Fulgêncio estaria fazendo referência a seu contexto de vida, informando as dificuldades que, de fato, enfrentava, bem como seu anseio por mudança política. Outros, como Hays (2003, p. 178), noutra via, já consideram a possibilidade de tais trechos se tratarem de mero topos literário. De qualquer forma, é interessante perceber que o Mitógrafo transparece possuir algum conhecimento sobre as ocupações mouras e a cidade de Alexandria, o que também pode ser considerado, num plano hipotético, como elemento informador de sua biografia.

Por fim, é oportuno expor que uma questão muito curiosa referente às Mythologiae diz respeito ao fato de que o problema da fortuna dos textos fulgencianos atinge, para além de divergências ortográficas, lexicais e aquelas vinculadas à autoria, aspectos de ordem estilística. Nesse sentido, um elemento que contribuiu para a gênese de um cenário imagético desfavorável

\footnotetext{
${ }^{5} \mathrm{O}$ evemerismo, atribuído a Evêmero de Messina (cerca de IV a.C.), diz respeito a uma corrente hermenêutico-filosófica que orienta à humanização dos deuses, entendidos como meras personagens históricas, no processo de interpretação dos mitos antigos. Assim, essa técnica foi muito utilizada por cristãos, a exemplo de Lactâncio, como forma de mitigar o paganismo.

${ }^{6}$ FVLG, myth. 1 praef. p. 5.

${ }^{7}$ FVLG, myth. 1 praef. p. 6.

${ }^{8}$ FVLG, myth. 1 praef. p. 9.
} 
ao Mitógrafo concerne à suposta composição de um poema em versos livres.

O que ocorreu, efetivamente, foi uma falha no processo de transmissão de seus escritos, visto que alguns códices separaram trechos de um mesmo verso, o que foi mantido na edição fixada por Helm (1898). Atualmente, a partir de um processo de reconstituição filológica, já se sabe que Fulgêncio escreveu com métrica perfeita - ressalvada uma discussão quanto à ársis através de tetrâmetros trocaicos cataléticos. A parte inicial do aludido poema foi representada desta maneira:

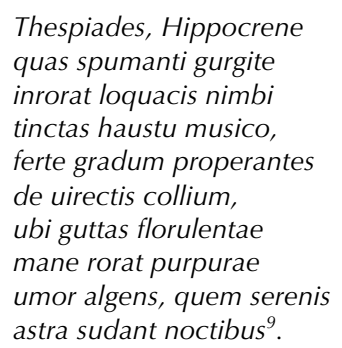

De fato, caso essa estrutura seja adotada para a análise métrica, não será constatada a presença de nenhum metro latino. Ocorre, contudo, que a forma adequada para a escansão é a seguinte:

$$
\begin{aligned}
& \text { Thespiades, Hippocrene quas spumanti gurgite } \\
& \text { inrorat loquacis nimbi tinctas haustu musico, } \\
& \text { ferte gradum properantes de uirectis collium, } \\
& \text { ubi guttas florulentae mane rorat purpurae } \\
& \text { umor algens, quem serenis astra sudant noctibus. }
\end{aligned}
$$

Assim, seguindo as regras de contagem de elementos do metro latino, verifica-se evidente a presença de versos estruturados em hemistíquios articulados em katà métron, quanto à existência de quatro dipodias trocaicas, com oitava sede formada exclusivamente por uma estrutura em indiferens, o que indica a quebra do pé. Tem-se, desse modo, a figura do tetrâmetro trocaico catalético.

\footnotetext{
${ }^{9}$ FVLG, myth. 1 praef. p. 7, 5-14. Na tradução lusófona, tem-se o seguinte: Ó Tespíades, as quais imersas no sorvo poético Hipocrene aspergiu de sua fonte espumante de borrifo loquaz, diligentes, fazei avançar o passo a partir dos verdores das colinas, onde, ao amanhecer, orvalha suores à florulenta púrpura o vapor frio, que os astros destilam em noites serenas.
} 


\section{Expositio sermonum antiquorum}

A Elucidação de Palavras Antigas, adotando-se a tradução de Almeida (2018), referese a uma espécie de glossário, formado por sessenta e dois verbetes conhecidos como sermones, que foram considerados arcaicos por Fulgêncio. Assim, julgando que tais vocábulos, presentes em obras clássicas, careciam de uma explicação mais detalhada para que fossem acessados por seus contemporâneos medievais, o Mitógrafo se dedicou à empreitada de sua descrição, inserindo-se, desse modo, em uma tradição enciclopédico-miscelânica de caráter lexicográfico.

No que tange às menções textuais atreladas ao conhecimento de seu autor, o conciso prólogo desperta atenção:

\footnotetext{
Ne de tuorum praeceptorum domine, serie, nostra quicquam curtasse inoboedientia putaretur, libellum etiam quem de abstrusis sermonibus impertiri iussisti, in quantum memoriae enteca subrogare potuit absolutum retribui, non faleratis sermonum studentes spumis quam rerum manifestationibus dantes operam lucidandis ${ }^{10}$.

Para evitar que a minha desobediência, ó senhor, fosse julgada de ter cortado algo da série de tuas recomendações, também o livrinho que, sobre as obscuras palavras, me ordenaste a preparar, entrego-o completo, a partir do quanto o acervo da memória pôde agregar, não me dedicando às babas ornadas dos sermões, mas consagrando a obra às revelações das coisas que devem ser elucidadas.
}

Tal excerto é paradigmático para a investigação biográfica de viés intratextual, tendo em vista que nele parece que Fulgêncio escrevia por encomenda, de modo que ele poderia exercer, profissionalmente, a ocupação de escritor, sendo remunerado por sua produção. Além disso, deve-se ressaltar o intenso apelo à memória, exaltado quanto ao processo de feitura do elucidário, o que pode sugerir que o Mitógrafo não dispunha de um fácil acesso a livros.

Igualmente, a preocupação em esclarecer o sentido de tais termos, tidos por antigos, também informa sobre a consciência do autor a respeito do estado de mudança linguística em que o latim se encontrava, cada vez mais distanciado daquele empregado no período clássico. Por fim, é interessante observar que, conforme Almeida (2018), o emprego de um termo restritivo ao qualificador absolutum ('completo') é indicativo de uma captatio beneuolentiae ${ }^{11}$.

10 FVLG, serm. ant. praef. p. 111.

11 A captatio beneuolentia é um termo relacionado à retórica latina que significa captação, conquista ou atração da benevolência, referindo-se a uma estratégia discursiva do autor para comover o leitor a desculpá-lo por eventuais falhas. 


\section{Expositio virgilianae continentiae}

Acolhendo a perspectiva de Moreira (2018), pode-se considerar a Explicação dos conteúdos de Virgílio como uma tradução fulgenciana intralingual da Eneida. Nesse sentido, é de se ressaltar que essa obra, como apontado por seu tradutor brasileiro, apresenta uma série de domesticações que a aproximam da conjuntura tardo-antiga na qual está inserida.

Assim, o escrito possui uma linguagem, por vezes, mais truncada, obscura e rebuscada que sua versão de partida, o que rendeu críticas mordazes ao Mitógrafo por parte de Comparetti, que não considerou esse texto digno de apreciação por "cérebros saudáveis" (1943, p. 60). Quanto a isso, deve-se compreender que a tradução em relevo não configura uma mera tentativa de copiar o poeta de Mântua, inserindo-se muito mais em um contexto de preservação da cultura clássica, garantidor da sobrevivência da tradição literária antiga, a partir, inclusive, de um conjunto de estratégias discursivas, como o uso de interpretações alegóricas e de etimologias.

Por fim, no que concerne às remissões feitas por Fulgêncio que podem indicar uma percepção do autor sobre si, Moreira (2018) sublinha o trecho Cui ego: serua ista quaeso tuis romanis ${ }^{12}$, traduzido por "Eu disse a ele: guarda isso para seus romanos". Essa passagem sugere um consciente distanciamento sócio-político entre o Autor e os habitantes do Lácio. Dessa maneira, embora o Mitógrafo pertença, manifestamente, a uma tradição cultural romana, considerava-se, nessa linha de intelecção, um escritor africano.

\section{De aetatibus mundi et hominis}

No conjunto da obra fulgenciana, seu lipograma afigura-se como o escrito mais cristão, assumindo uma posição particular pela forma de abordagem da sua temática, responsável por fornecer inúmeras pistas quanto aos fundamentos ideológicos do escritor. Narra-se o percurso histórico da humanidade, em fases de glória e de decadência, a partir de figuras como Eva, Adão, Caim, Abel, Noé, Abraão, Moisés, Saul e Cristo, processo em que se revela, inclusive, uma influência do pensamento filosófico-teológico de Santo Agostinho. O Mitógrafo aborda, portanto, como o próprio nome da obra já sugere, as idades do mundo e do homem, inserindo-

\footnotetext{
${ }^{12}$ FVLG, Virg. cont. p. 86.
} 
se, quanto ao tema do lipograma, em uma tradição da qual pertencem autores antigos, como Esopo, Empédocles, Hesíodo, Sêneca e Ovídio, muito embora inove através do elemento cristão, basilar de seu cabedal literário.

Na tentativa de extrair pistas para o conhecimento de Fulgêncio, desperta atenção, preliminarmente, o fato de que essa produção, apesar de possuir uma temática de pretendido viés histórico, não apresenta datações, o que eleva os desafios enfrentados pelos biógrafos. De qualquer modo, a primeira parte da De aetatibus já fornece alguns elementos:

Oportuit quidem, uirorum excellentior, hoc nostro quo nuper regimur temporis cursu perenni potius studere silentio et non dicendi studio, praesertim ubi nihil plus nisi de nummi quaestu res uertitur et conquirendi lucri perennis sollicitudo cotidie mentibus suppuretur; cupido etenim sensui non sermo dicentis comptior, sed offerentis est dulcior. In his non lugentum luctus intenditur, non miserorum gemitus condoletur, sed solius colligendae pecuniae commodo pernox compotus ducitur; cupidae enim menti fit et uox humilis ${ }^{13}$.

Foi, certamente, oportuno, ó mais excelente dos homens, neste nosso curso perene de tempo pelo qual recentemente somos governados, pensar ao invés de ficar em silêncio, mas não ficar pensando em falar, principalmente quando nada além do ganho de dinheiro move as ações, e a perene ambição de auferir lucro seja quotidianamente supurada pelas mentes humanas. Para quem tem sentimentos de cobiça, com efeito, não é mais elegante a linguagem de quem diz, entretanto é mais doce a de quem oferece. Entre estes, o lamento dos lamentosos não é observado, o gemido dos miseráveis não recebe compaixão, mas o cálculo que dura toda a noite é computado, com o propósito de que cada tostão seja devidamente recolhido.

Do exposto, é interessante perceber a existência de um certo padrão na obra fulgenciana, em que o autor continuamente destaca, nas introduções, a dificuldade do empreendimento artístico-literário. Se, nas Mythologiae, ressalta o contexto belicoso e, na Sermonum, a necessidade de memorizar um conjunto de informações, o que sugere uma dificuldade de acesso a livros, aqui já se destaca um certo desinteresse do público, mais preocupado com o próprio ganho. Saliente-se, ademais, que a crítica do Mitógrafo, também associada a uma captatio beneuolentia, constrói-se dentro de uma feição mais cristã, visto que se volta contra o pecado da avareza. Em seguida, ainda no prólogo, verifica-se outro trecho digno de consideração:

Ergo praetermissis libelli principiis rerum nobis exhinc sumendus est tenor. Viginti igitur et duobus elementis penes Hebreos ordo loquendi disponitur, uno itidem superiecto nostrae linguae profusio, sed et Rom<an>ae colligitur;

${ }^{13}$ FVLG, de aetat. praef, p. 129. 


\begin{abstract}
sin uero tertiae sequentem litterae superieceris signum, Grecae linguae necesse est integrum ut monstretur effectum. Ergo ex quo in his operibus Grecum praecessit ingenium, oportet deinceps nostrae linguae medium ordinem consequi, quo non bis duodeno uel bis undeno, sed Grecis uno elemento subducto et Hebreis uno superinposito unicus ordo Libico monstretur in numero. His ergo uiginti et tribus elementorum figuris, in quibus uniuersus loquendi cursus colligitur, mundi ipsius hominisque discretis temporibus ordines coaequemus necesse est ${ }^{14}$.

Portanto, deixados de lado os princípios do libelo, desses nossos feitos, se dê a continuação que deve ser conduzida. Por conseguinte, entre os Hebreus, o alfabeto dispõe de vinte e dois elementos. A profusão de nossa língua, mas que é também aquela de Roma, é enriquecida, similarmente, por um único a mais, mas se, em verdade, tu acrescentasses o sinal sucessivo da terceira letra, necessariamente teria sido indicado toda a potência da língua grega. Portanto, visto que nestas obras precedeu o engenho grego, é oportuno seguir, sucessivamente, a ordem média da nossa língua, em que não há duas vezes doze ou duas vezes onze, mas subtraído um elemento aos gregos e adicionado um aos hebreus, se indica a ordem única em registro líbico. Portanto, a estes vinte e três caracteres de letras, nos quais se obtém o curso universal da fala, é necessário que comparemos, diferenciados os tempos, as ordens do próprio mundo e do homem.
\end{abstract}

Esse segundo excerto, por fim, fornece sinais indicadores da percepção do Mitógrafo sobre sua própria língua, representando também um vestígio para estudos em sociolinguística. Nele, Fulgêncio considera que seu latim líbico seria formado por vinte e três letras, muito embora o alfabeto clássico tenha apenas vinte e dois caracteres. Com base nisso, Whitbread (1971) considera que a letra adicional seria o ' $y$ '. Essa passagem é, portanto, muito relevante, pois testemunha a mudança linguística em curso, acentuando diferenças entre o latim clássico e o africano-medieval.

\title{
Considerações Finais
}

Se na atualidade é relativamente fácil obter um conjunto preciso de dados biográficos dos autores contemporâneos, o mesmo não pode, em muitos instantes, ser dito quanto a textualidades antigas. Nesse sentido, em inúmeros casos, como no de Fábio Plancíades Fulgêncio, até a concepção da existência do autor se faz, sobretudo, a partir de sua própria obra, por esta ter sido um dos poucos elementos supérstites.

Desse modo, um estudioso de escritos pertencentes a temporalidades remotas e, especialmente, da produção fulgenciana deve ter muita cautela e criticidade quanto ao processo

\footnotetext{
${ }^{14}$ FVLG, de aetat. praef, p. 131.
} 
de transmissão textual, tensionando continuamente os subsídios fornecidos pela tradição. Assim, a partir de uma série de indagações, incluindo aspectos de cunho estilístico, propiciou-se uma inflexão na hipótese unitária, que considerava o Mitógrafo e o Ruspense como um único sujeito.

Hoje a maior parte da crítica já defende a existência de dois autores diversos, o que acabou despertando o interesse de alguns pesquisadores pela busca de sinais e vestígios sugestivos de dados biográficos. Essa empreitada se demonstra, por óbvio, conturbada e, muitas vezes, questionável, mas possui o mérito de também proporcionar um maior conhecimento da produção estética de seu compositor.

\section{Referências:}

ALMEIDA, Shirlei. A 'Expositio Sermonum Antiquorum', de Fulgêncio, o Mitógrafo: estudo introdutório, tradução e notas. Dissertação (Mestrado em Literatura e Cultura) PPGLitCult, Universidade Federal da Bahia, Salvador, 2018.

AMARANTE, José. O livro das Mitologias de Fulgêncio. Os mitos clássicos e a filosofia moral cristã. Salvador: Edufba, 2019.

AMARANTE, J. L'architettura orizzontale dei tre libri delle Mythologiae di Fulgenzio, SIFC 2 (2018), pp. 157 200.

AMARANTE, José. A explicação fulgenciana para o surgimento dos deuses: um amálgama pagão-cristão? Revista Hypnos, São Paulo, v. 41, $2^{\circ}$ sem., 2018, p. 215-236.

COMPARETTI, D. Virgilio nel medioevo. Florença: La Nuova Itália, 1943.

ENO, Robert. Fulgentius of Ruspe: selected works. Revista Fathers of the Church; v. 95, 1996.

FULGENTII, F. Opera. Edição de Rudolf Helm. Lipsiae: Teubner, 1898.

GEMBLOUX, S; TRITEMIUS, J. De scriptoribus ecclesiasticis. Frankfurt: Witte, 1974.

HAYS, G. Fulgentius the Mythographer. 1996. 402 f. Tese (Doutorado em Filosofia) - Cornell University, New York.

HOMMEY, Jacob. Liber absque litteris De aetatibus mundi et hominis, absque A. absque B., etc. Lutetiae Parisiorum, 1696.

JUNGMANN, E. Quaestiones Fulgentianae. Act. Soc. Philol. Lips. n. 1. 1870.

JUNGMANN, E. Die Zeit des Fulgentius. Berlin: 1877.

MANCA, M (a cura di). Le età del mondo e dell'uomo. Allesandria: Edizioni dell'Orso, 2003.

MODÉRAN, Yves. La chronologie de la Vie de saint Fulgence de Ruspe et ses incidences sur I'histoire de I'Afrique vandale. In: Mélanges de l'École française de Rome. Revista Antiquité, tome 105, n¹. 1993. pp. 135-188

MOREIRA, Raul. A "Exposição dos conteúdos de Virgílio", de Fulgêncio: estudo introdutório e tradução anotada. Dissertação (Mestrado em Literatura e Cultura) PPGLitCult, Universidade Federal da Bahia, Salvador, 2018. 
PENNISI, G. Fulgenzio e la Expositio sermonum antiquorum. Firenze: Felice Le Monnier, 1963.

PIZZANI, U. Fulgenzi: definizione di parole antiche. Roma: Ateneo, 1968.

REIFFERSCHEID. Mittheilungen aus Handschriften. Heildeberg: RhM, 1868.

REIFFERSCHEID. Anecdotum Fulgentianum. Bratislava, 1883.

ROSA, Fabio. Fulgenzio: Commento all'Eneida. Milano-Trento: F. R., 1997.

STRZELECKI. Quaestiones tragicae. Eos, 1952.

VENUTI, M. Il prologo delle Mythologiae di Fulgenzio: Analisi, traduzioni, commento. 2009. 324 f. Tese (Doutorado em Letras Clássicas) - Università degli Studi di Parma, Parma.

VENUTI, M. Il prologus delle Mythologiae di Fulgenzio. Introduzione, testo critico, traduzione e commento. Napoli: Paolo Loffredo Iniziative Editoriali s.r.l., 2018. 